\title{
Association Between Neutrophil-Lymphocyte Ratio and Oncotype Dx Recurrence Score in Early-Stage Hormonal Receptor-Positive, HER2-Negative, Node-Negative Breast Cancer
}

\author{
Bader Alshamsan (1D ${ }^{1,2}$ \\ Aisha Alshibany' \\ Mahmoud A Elshenawy ${ }^{1,3}$ \\ Ahmed Badran (D) ${ }^{1,4}$ \\ Tusneem Elhassan' \\ Dahish Ajarim' \\ Adher Alsayed' \\ Kausar Suleman' \\ Taher Al-Tweigeri ${ }^{1}$ \\ 'Medical Oncology, Oncology Center, \\ King Faisal Specialist Hospital \& Research \\ Centre, Riyadh, Saudi Arabia; \\ ${ }^{2}$ Department of Medicine, College of \\ Medicine, Qassim University, Qassim, \\ Saudi Arabia; ${ }^{3}$ Clinical Oncology, Faculty \\ of Medicine, Menoufia University, \\ Shebeen El-Kom, Egypt; ${ }^{4}$ Clinical \\ Oncology Department, Ain Shams \\ University Hospitals, Cairo, Egypt
}

Correspondence: Bader Alshamsan Email bshmsan@qu.edu.sa
Purpose: The correlation between the preoperative neutrophil-to-lymphocyte ratio (NLR) and Oncotype DX ${ }^{\circledR}$ (ODX) recurrence score (RS) has not yet been established. We aimed to investigate the association between NLR and ODX RS in patients with hormone receptor-positive (HR+) and human epidermal growth factor receptor 2-negative (HER2-) early-stage breast cancer (BC).

Patients and Methods: This retrospective study included consecutive patients with HR +/HER2-, node-negative primary BC who underwent surgical tumor resection from 2011 to 2019. Receiver operating characteristic curve analysis was used to obtain an optimal NLR cutoff value. Logistic regression analyses were used to estimate associations between various parameters and ODX RS. Furthermore, the factors significantly associated with the ODX RS in multivariable analysis were incorporated in a separate model and estimated using logistic regression.

Results: A total of 160 patients were enrolled. The optimal preoperative NLR cutoff was 2.15. Multivariable analysis revealed that NLR and tumor grade (G1/G2 vs G3) were independent predictive factors of high RS cutoff $(\geq 26)$. Moreover, including the two variables yielded a stronger association; patients with low NLR and low-grade tumors were unlikely to have high RS $(\geq 26$; odds ratio $[\mathrm{OR}]=0.03,95 \%$ confidence interval $[\mathrm{CI}]: 0.006-0.154 ; \mathrm{p}<0.001)$. Conversely, the presence of any of the following factors made patients unlikely to have low $\mathrm{RS}(<16$; OR $=0.34$, 95\% CI: 0.16-0.73; $p=0.006)$ : high NLR, high grade, or high Ki-67 levels $(>20)$.

Conclusion: NLR is a promising independent predictor of RS. Furthermore, in addition to tumor grade and Ki-67 level, they together are also a potential indicator of high and low RS. However, further studies are required to validate this hypothesis.

Keywords: neutrophil-to-lymphocyte ratio, Oncotype Dx recurrence score, early-stage breast cancer, hormonal receptor-positive, human epidermal growth factor receptor 2-negative, node-negative breast cancer

\section{Introduction}

Breast cancer (BC) is the most frequently diagnosed cancer in women and the most frequent cause of cancer-related deaths worldwide. ${ }^{1} \mathrm{BC}$ accounted for an estimated $24.5 \%$ of all new cancer cases and $15.5 \%$ of all cancer-related mortalities in $2020{ }^{1}$ In general, four major biological subtypes of $\mathrm{BC}$ are identifiable: hormone receptorpositive $(\mathrm{HR}+)$ and human epidermal growth factor receptor 2-negative (HER2-) Luminal A, Luminal B, HER2-enriched, and triple-negative disease. ${ }^{2-4}$ The HR +/HER2- subtype represents most common BC molecular subtypes, ranging from 
$59 \%$ to $75 \%$ of cases. $^{2-6}$ Multidisciplinary approaches to reduce $\mathrm{BC}$ mortality include surgery, chemotherapy \pm targeted therapy \pm hormonal therapy, and radiation therapy. ${ }^{7}$ The utilization of systemic adjuvant chemotherapy has aided in the decline in cause-specific recurrence and mortality, and it is now recognized as the standard of care. ${ }^{8-10}$ Oncotype $\mathrm{DX}^{\circledR}(\mathrm{ODX})$ recurrence score $(\mathrm{RS})$ assay is a multigene reverse transcription-polymerase chain reaction that measures the transcriptional activities of 21 genes (16 cancer-associated and 5 housekeeping genes) and uses the expression pattern to calculate RS (range: 0$100)$ that predicts the 10-year risk of $\mathrm{BC}$ recurrence; this assay has been incorporated into early $\mathrm{BC}$ management and is used widely to determine appropriate candidates for adjuvant chemotherapy. ${ }^{11-18}$

Inflammation and the immune system are major hallmarks of malignancy. ${ }^{19}$ Neutrophil-to-lymphocyte ratio (NLR) is the ratio of absolute neutrophil counts to absolute lymphocyte counts in the peripheral blood. NLR reflects the host's inflammatory and immune responses to cancer, which plays crucial roles in carcinogenesis. ${ }^{20-22}$ The neutrophilic response stimulates tumor growth and inhibits the immune system by suppressing the cytotoxic activity of T cells and is associated with poor prognosis. ${ }^{19,23}$ Lymphocytopenia is associated with adverse outcomes in patients with cancer. ${ }^{24,25}$

Several predictive models built using clinicopathological variables have been suggested to be surrogate markers for $\mathrm{RS}^{26}$ NLR has not been included with these factors, and the relationship between NLR and RS has not been established yet; however, NLR has been identified as an independent prognostic factor for disease-free survival (DFS) and overall survival (OS) in a variety of solid tumors, ${ }^{27-30}$ including $\mathrm{BC} .^{25,31-34}$ A study reported no correlation between ODX RS and NLR, ${ }^{35}$ although current theories support the hypothesis that such a correlation might exist. Immunological biomarkers are of high prognostic value when used in addition to other clinicopathological factors. ${ }^{36}$ The diversity in tumor gene expression of luminal $\mathrm{HR}+{ }^{37}$ is related to immune cell infiltration and host immune response. $^{33,38}$ The correlation of NLR with RS could provide an additional valuable biomarker that is available for clinical utilization during BC management. We aimed to investigate the relationship between preoperative NLR and other clinicopathological factors with ODX RS in patients with HR+/HER2-, node-negative
$\mathrm{BC}$ who underwent surgical resection of the primary tumors.

\section{Patients and Methods Study Patients}

We retrospectively identified all patients diagnosed with HR +/HER2-, and node-negative BC who met the inclusion criteria from January 2012 to February 2020. This study was conducted in accordance with the guidelines for reporting tumor marker studies in BC research and treatment. ${ }^{39,40}$ The study protocol was approved by the Medical Ethics Committee of the Research Advisory Council at the King Faisal Specialist Hospital \& Research Centre, and was conducted according to the ethical principles of the Declaration of Helsinki (2000). The participants remained anonymous, and no identifying or protected health information was recorded; hence, the ethics committee waived the requirement for informed consent.

The inclusion criteria were as follows: 1) age, 18-65 years; 2) patients with early-stage HR+/HER2-, and nodenegative $\mathrm{BC}$ who had undergone surgical removal of the tumors and underwent the ODX 21-gene RS assay test; and 3) the availability of a differential leukocyte count recorded before surgery. The upper age limit was 65 years based on our knowledge of underuse of ODX RS in patients older than 65 years due to chemotherapy tolerability and the association of older age with NLR. ${ }^{41,42}$

The exclusion criteria were as follows: 1) a lack of information regarding pathologic or laboratory results; 2) pregnancy-related $\mathrm{BC}$; 3) ductal carcinoma in situ; 4) hormone receptor-negative, HER2-positive, or node-positive diseases; 5) stage IV BC or inflammatory BC; 6) systemic clinical evidence of active infection; 7) hematological disorders; 8) prior steroid therapy; 9) chronic obstructive pulmonary disease requiring treatment; 10) chronic liver disease; 11) end-stage renal disease; 12) history of a cerebrovascular accident; and/or 13) systemic lupus erythematosus.

\section{Patient Data Collection}

The data were retrieved from a prospective database at the King Faisal Specialist Hospital \& Research Centre, Riyadh, Saudi Arabia. The medical records of each patient were reviewed independently by two physicians for the baseline characteristics in terms of patient demographics and clinicopathological data, including age, menopausal status, tumor size, grade, lymph node status, Ki-67 protein levels, presence/absence of lymphovascular invasion (LVI), hormonal 
receptor expression, HER2 status, comorbidities, and obesity (body mass index $[\mathrm{BMI}] \geq 30 \mathrm{~kg} / \mathrm{m}^{2}$ ).

A specialized $\mathrm{BC}$ pathologist confirmed all pathology slides. $\mathrm{HR}+\mathrm{BC}$ was defined as tumor cells stained $\geq 1 \%$ on immunohistochemistry (IHC) for estrogen and/or progesterone receptors. However, ODX RS was only ordered based on our guidelines for patients with an ER of $\geq 10 \%$. HER2- BC was defined as IHC staining of $0,1+$, or confirmed negative fluorescence in situ hybridization findings if IHC was equivocal (2+) and HER2 to CEP17 ratio was $<2$ with a HER2 copy number of $<4$. Tumor grade was determined based on the Nottingham histologic grade. Ki-67 was classified as low $(\leq 20 \%)$ or high $(>20 \%)$. White blood cells with differential diagnoses were obtained after the initial diagnosis and confirmed before curative breast surgery. Preoperative NLR was calculated as the quotient of the absolute neutrophil count divided by the absolute lymphocyte count. ODX RS was performed on paraffin-embedded tumor samples at the Exact
Sciences Corp, Madison, Wisconsin. The patients were stratified based on the ODX RS into high-risk ( $\geq 26)$ vs intermediate/low-risk $(<26)$, and low-risk $(<16)$ vs intermediate/highrisk $(\geq 16)$ groups. These cutoffs were determined according to the NCCN guidelines for node-negative diseases. ${ }^{16}$ If RS is $<26$ or $<16$, there is no additional benefit of chemotherapy in post-menopausal and pre-menopausal women, respectively. Additional chemotherapy is recommended when RS is $\geq 26$ in post-menopausal and pre-menopausal women. ${ }^{43}$

\section{Statistical Analysis}

Categorical variables are described as frequencies and were compared using the Chi-square test and continuous variables as median values with interquartile range (IQR) and compared using the Mann-Whitney U-test. Pearson's correlation coefficient was used to assess the correlation between continuous variables. The optimal NLR cutoff was obtained by a receiver operating characteristic curve

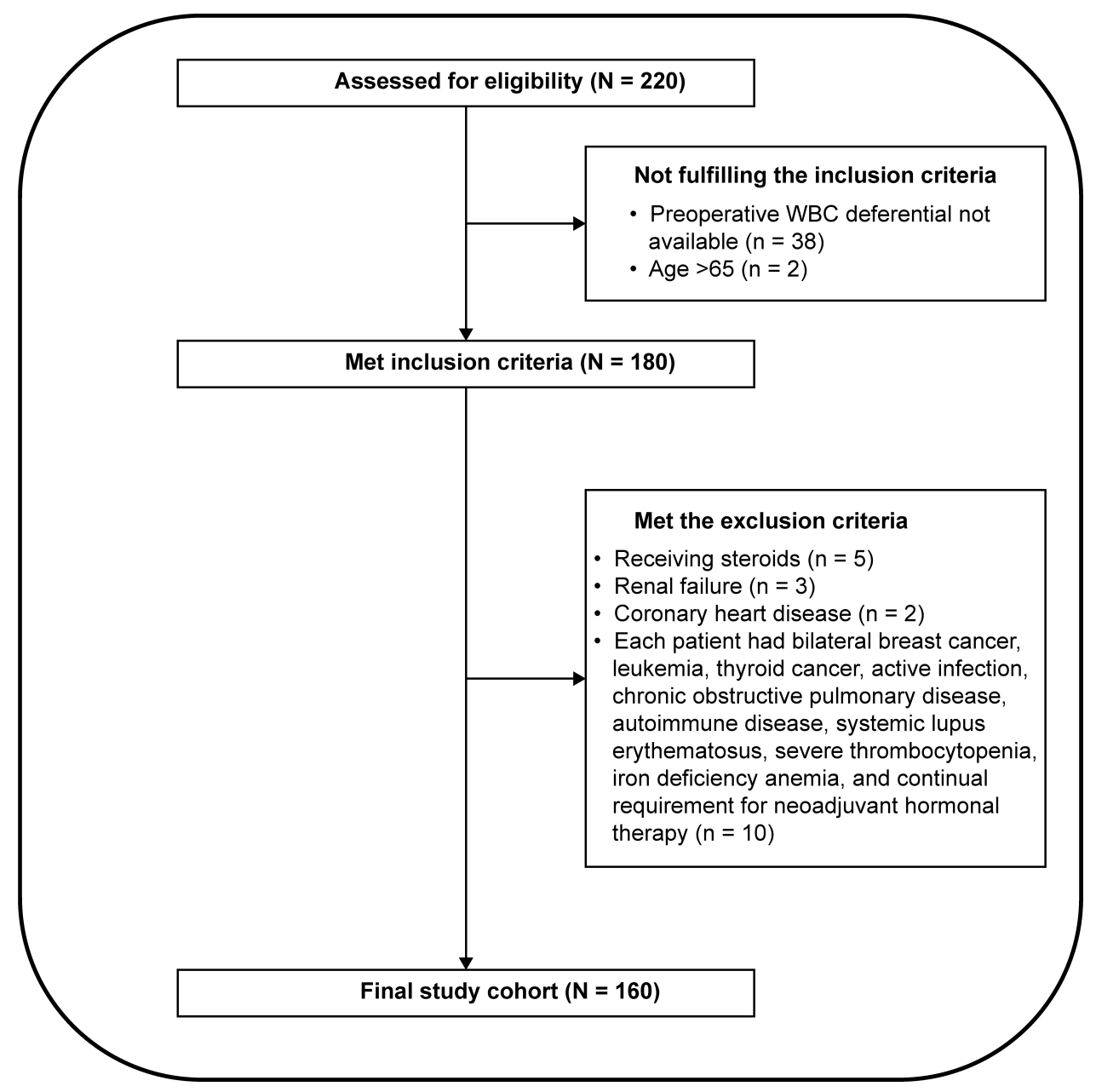

Figure I Flow diagram for selection criteria. 
(ROC). ${ }^{33,44}$ Associations between various parameters and the RS cutoff values of 16 and 26 were estimated using univariable and multivariable binary logistic regression analyses. The variables included were age, menopausal status, tumor grade, Ki-67 level ( $\geq 20 \%$ or $\leq 20 \%$ ), LVI, T stage, NLR, platelet-to-lymphocyte ratio (PLR), BMI, and comorbidities. The clinicopathological factors that remained significant in multivariable analysis were incorporated in separate models and evaluated to predict RS using logistic regression. DFS was estimated using the Kaplan-Meier method. Statistical significance was set at a p-value of $<0.05$, and all statistical analyses were performed using SPSS for Mac, v27 (IBM Corp, Armonk, NY, USA).

\section{Results}

A total of 160 patients were included in the final analysis (Figure 1). The median age at diagnosis was 49 years (IQR: 42-56 years). Patient demographics and disease characteristics are shown in Table 1 . The median NLR was 1.61 (IQR: 1.21-2.15), and there was a significant association between NLR and RS $(r=0.29, \mathrm{p}<0.001)$. There was no association between RS and PLR $(p=0.59)$, lymphopenia $(p=0.74)$, or BMI $(p=0.59)$. The ROC curve revealed an optimal NLR cutoff point of 2.15 (Figure 2). Patients were stratified into the low- and highNLR groups based on the NLR cutoff point of 2.15, as shown in Table 2 . The variables tested in the univariate analyses were age, menopausal status, tumor grade, LVI, $\mathrm{T}$ stage, Ki-67 status, obesity, and comorbidities. Multivariable analysis showed that NLR and tumor grade remained significant predictors of ODX RS of $\geq 26$. The NLR, tumor grade, and Ki-67 status remained significant predictor of ODX RS of $<16$ (Table 3).

The significant predictive factors of ODX RS of $>26$ were combined, and patients were classified into four groups: low NLR and low grade, low NLR and high grade, high NLR and low grade, and high NLR and high grade. There was a significant difference between the groups as measured by the Pearson's Chi-square test ( $p<0.001$; Figure 3A). Logistic regression analysis revealed that compared with high NLR and high grade (G3), all other groups showed lower odds of RS of $\geq 26$ (odds ratio $[\mathrm{OR}]=0.3,95 \%$ CI: $0.006-0.154, \mathrm{p}<0.001$; $\mathrm{OR}=0.14,95 \%$ CI: $0.023-0.85, \mathrm{p}<0.03$; and $\mathrm{OR}=0.05$, $95 \%$ CI: $0.01-0.34, \mathrm{p}<0.002$ for low NLR and low grade, low
Table I Patients Demographics and Disease Characteristics $(n=160)$

\begin{tabular}{|c|c|}
\hline Characteristics & Frequency (\%) \\
\hline \multicolumn{2}{|l|}{ Menopausal } \\
\hline Pre & $99(61.9)$ \\
\hline Post & $61(38.1)$ \\
\hline \multicolumn{2}{|l|}{ Tumor Grade } \\
\hline I & $22(13.8)$ \\
\hline 2 & $109(68.1)$ \\
\hline 3 & $29(18.1)$ \\
\hline \multicolumn{2}{|l|}{ ER } \\
\hline Positive & $159(99.4)$ \\
\hline Negative & I $(0.6)$ \\
\hline \multicolumn{2}{|l|}{ PR } \\
\hline Positive & I5I (94.4) \\
\hline Negative & $9(5.6)$ \\
\hline \multicolumn{2}{|l|}{ LVI } \\
\hline Positive & $38(23.8)$ \\
\hline Negative & $120(75)$ \\
\hline Missing & 2 \\
\hline \multicolumn{2}{|l|}{ T stage } \\
\hline I & $84(52.5)$ \\
\hline 2 & $72(45)$ \\
\hline 3 & 4 \\
\hline \multicolumn{2}{|l|}{ Ki-67 } \\
\hline$(\leq 20)$ & $95(59.4)$ \\
\hline$(>20)$ & $62(38.8)$ \\
\hline Missing Oncotype Dx & 3 \\
\hline$<16$ & $62(38.8)$ \\
\hline$\geq 16$ & $98(6 \mid .3)$ \\
\hline$\geq 26$ & $34(21.3)$ \\
\hline$<26$ & $126(78.8)$ \\
\hline \multicolumn{2}{|l|}{ BMI } \\
\hline$\geq 30$ & 81 (50.9) \\
\hline$<30$ & $78(49)$ \\
\hline Missing & I \\
\hline \multicolumn{2}{|l|}{ Comorbidities $^{\mathrm{a}}$} \\
\hline Present & $44(27)$ \\
\hline Absent & $116(72.5)$ \\
\hline
\end{tabular}

Notes: ${ }^{a}$ Comorbidities not under exclusion criteria: diabetes mellitus, hypertension, dyslipidemia, depression, hypothyroidism, and obesity.

Abbreviations: BMI, body mass index; ER, estrogen receptor; LVI, lymphovascular invasion; PR progesterone receptor. 


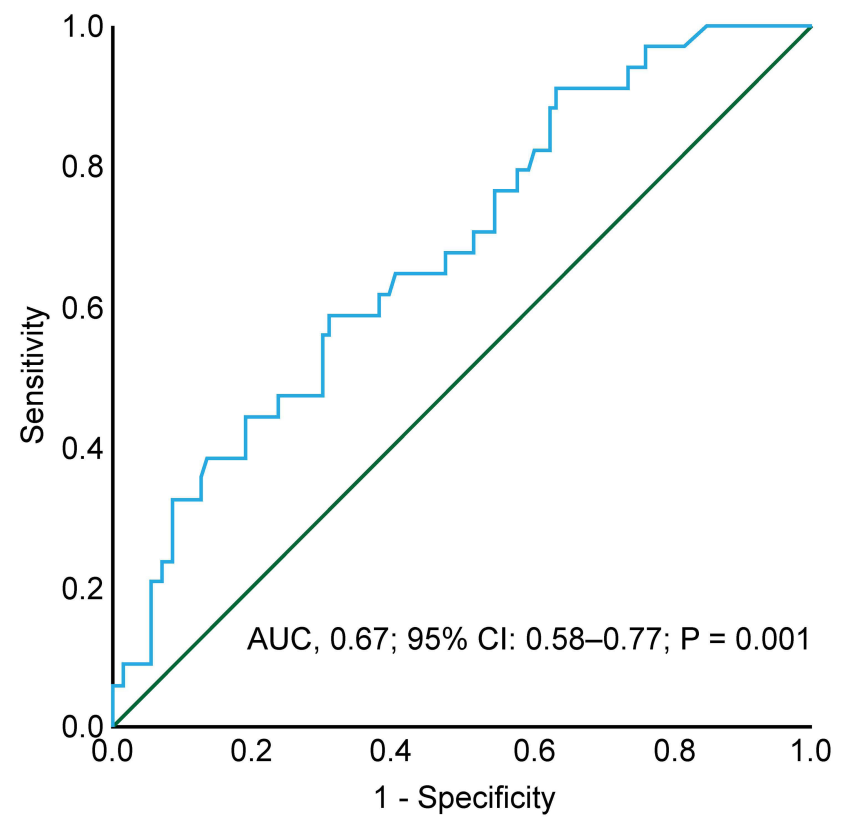

Figure 2 ROC curve showed that neutrophil-to-lymphocyte ratio associated with Oncotype Dx and the cutoff point of 2.15 revealed 0.81 and 0.60 sensitivity and specificity, respectively.

NLR and high grade, and high NLR and low grade groups, respectively).

The significant predictive factors of ODX RS of $<16$ were combined, and the patients were classified into four groups according to the number of risk factors (high category: Ki-67 $>20, \mathrm{G} 3$ or NLR $\geq 2.15$ ). There was a significant difference between the groups $(\mathrm{p}<0.001$; Figure 3B). Logistic regression revealed that compared with patients without any risk factors in high categories, the presence of any of the factors in the high category was associated with a lower odds of ODX RS of $<16$ (OR $=0.34 ; 95 \%$ CI: 0.16 $0.73 ; \mathrm{p}=0.006)$. The presence of two factors in the high category was associated with a lower odds of ODX RS of $<16(\mathrm{OR}=0.12 ; 95 \%$ CI: $0.03-0.38 ; \mathrm{p}<0.001)$; the presence of all three factors in the high category was associated with an OR of 0.10 (95\% CI: $0.01-0.92 ; p=0.04$ ).

The median follow-up duration was 30 months (IQR 1657 months). There were 12 recurrence cases and four deaths reported in the analysis. The 5-year DFS of the low NLR group $(<2.15)$ and high-NLR group was $88.8 \%$ and $86.1 \%$, respectively $(p=0.49)$, whereas for patients with NLR in the first quartile $(<1.22)$, the 5-year DFS rate was $100 \%$ and $82.7 \%(\mathrm{p}=0.02)$, respectively. The 5-year DFS for ODX $\geq 26$ and $<26$ groups was $77.4 \%$ and $90.2 \%(p=0.09)$, respectively, and for the ODX $<16$ and $\geq 16$ groups was $97.4 \%$ and $81.9 \%$, respectively $(p=0.13$; Figure $4 A-D)$.
Table 2 Patients and Disease Characteristics Stratified Based on Low and High NLR

\begin{tabular}{|c|c|c|}
\hline \multirow[t]{2}{*}{ Characteristics } & $\begin{array}{l}\text { High NLR } \geq 2.15 \\
(n=40)\end{array}$ & $\begin{array}{l}\text { Low NLR }<2.15 \\
(n=120)\end{array}$ \\
\hline & n (\%) & n (\%) \\
\hline Median age (IQR) & $48.5(42-56.5)$ & $49(42-56)$ \\
\hline Pre-menopausal & $24(60)$ & $75(62.5)$ \\
\hline \multicolumn{3}{|l|}{ Tumor Grade } \\
\hline 1 & $7(17.5)$ & $15(12.5)$ \\
\hline 2 & $22(55)$ & $87(72.5)$ \\
\hline 3 & II (27.5) & $18(15)$ \\
\hline ER-positive & $40(100)$ & $119(99.2)$ \\
\hline PR-positive & $36(90)$ & $115(95.8)$ \\
\hline LVI-positive & $9(22.5)$ & $29(24.6)$ \\
\hline \multicolumn{3}{|l|}{$\mathrm{T}$ stage } \\
\hline 1 & $21(52)$ & $63(52.5)$ \\
\hline 2 & $18(45)$ & $54(45)$ \\
\hline 3 & $\mathrm{I}(2.5)$ & $3(2.5)$ \\
\hline \multicolumn{3}{|l|}{ Ki-67 level } \\
\hline$\leq 20$ & $24(60)$ & 7I (59.2) \\
\hline$>20$ & $16(40)$ & $46(38.3)$ \\
\hline \multicolumn{3}{|l|}{ Oncotype Dx } \\
\hline$<16(62 / 160)$ & $9(22.5)$ & $53(44.2)$ \\
\hline$\geq 16(98 / 160)$ & $31(77.5)$ & $67(55.8)$ \\
\hline$\geq 26(34 / 160)$ & $15(37.5)$ & $19(15.8)$ \\
\hline$<26(126 / 160)$ & $25(62.5)$ & $101(84.2)$ \\
\hline $\mathrm{BMI} \geq 30 \mathrm{~kg} / \mathrm{m}^{2}$ & $62(52.1)$ & $19(47.5)$ \\
\hline $\mathrm{BMI}<30 \mathrm{~kg} / \mathrm{m}^{2}$ & $57(47.9)$ & $21(52.5)$ \\
\hline Presence of Comorbidities & $12(30)$ & $32(26.7)$ \\
\hline
\end{tabular}

Abbreviations: ER, estrogen receptor; IQR, interquartile range; LVI, lymphovascular invasion; NLR, neutrophil-to-lymphocyte ratio; PR progesterone receptor.

\section{Discussion}

Early-stage HR+, HER2-, and node-negative BC is generally considered to have a low risk of recurrence. However, highly useful tools might enable the distinction of patients who would not require postoperative chemotherapy from those likely to be at high risk requiring adjuvant postoperative chemotherapy; this information would prove critical for strategic planning regarding monitoring and management of patients. ODX RS is a test that predicts the benefits of chemotherapy and the need 
Table 3 Multivariate Logistic Regression Analysis for ODX RS Cutoffs

\begin{tabular}{|c|c|c|c|c|c|c|}
\hline & \multicolumn{3}{|c|}{ Oncotype Dx $\geq 26$} & \multicolumn{3}{|c|}{ Oncotype Dx $<16$} \\
\hline & OR & $95 \% \mathrm{Cl}$ & p-value & OR & $95 \% \mathrm{Cl}$ & p-value \\
\hline \multicolumn{7}{|l|}{ Menopausal status } \\
\hline Pre-menopausal & I & & & I & & \\
\hline Post-menopausal & 1.25 & $0.49-3.13$ & 0.63 & 1.4 & $0.69-2.86$ & 0.34 \\
\hline \multicolumn{7}{|l|}{ NLR } \\
\hline$<2.15$ & I & & & I & & \\
\hline$\geq 2.15$ & 5.4 & $1.2-8.05$ & 0.01 & 0.39 & $0.16-0.92$ & 0.03 \\
\hline \multicolumn{7}{|l|}{ Tumor Grade } \\
\hline GI/G2 & I & & & I & & \\
\hline G3 & 5.12 & $1.89-15.38$ & $<0.01$ & 0.25 & $0.06-0.95$ & 0.04 \\
\hline \multicolumn{7}{|l|}{ Ki-67 level } \\
\hline$\leq 20$ & I & & & I & & \\
\hline$>20$ & 1.86 & $0.03-6.5$ & 0.57 & 0.43 & $0.19-0.95$ & 0.03 \\
\hline
\end{tabular}

Abbreviations: $\mathrm{Cl}$, confidence interval; NLR, neutrophil-to-lymphocyte ratio; ODX RS, Oncotype DX recurrence score; OR, odds ratio.

for more aggressive treatment. In real-world clinical practice, the use of ODX RS is found to be beneficial in the management of more than one-third of the patients with BC. ${ }^{45}$ The patients treated based on ODX RS had better BC-specific survival and OS; however, limited healthcare access for social or ethnic minorities in developed countries and the unavailability of the test in some parts of the world remain a challenge. ${ }^{46}$ Researchers have attempted to identify a link between the histopathological factors associated with $\mathrm{BC}$ recurrence to build a tool that can provide information similar to ODX RS. The modified Magee equations $1-3^{47}$ and Gage et $\mathrm{al}^{48}$ showed a significant correlation between histopathological factors and ODX RS; in particular, in patients with clearly high or low predicted risk, RS is unlikely to be different. ${ }^{47}$ Furthermore, combining clinicopathological factors and RS did provide more prognostic information. ${ }^{49}$ Thus, it is recommended to consider this tool when selecting patients for endocrine therapy alone. ${ }^{49-51}$ Moreover, recently, a new prognostic tool that combined clinicopathological factors and ODX RS was able to provide more predictive information to
A

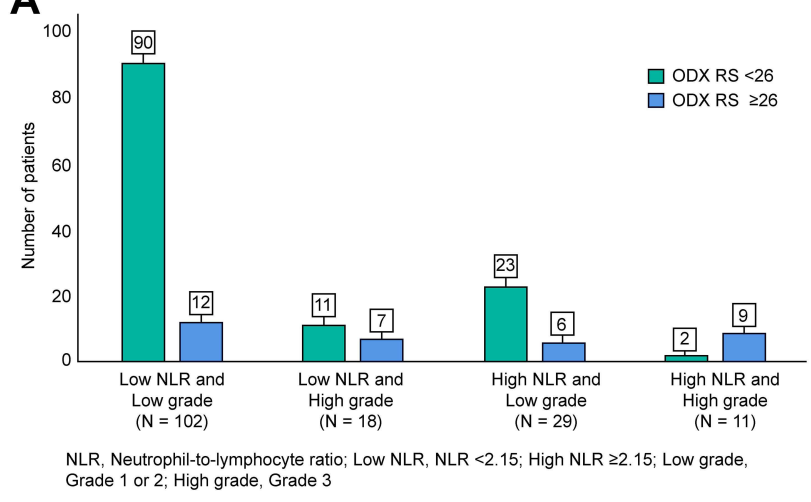

B

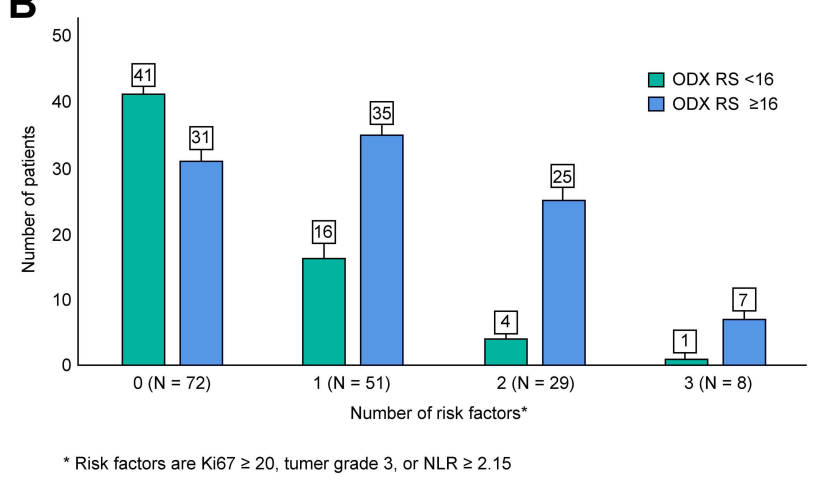

Figure 3 Illustration showing the patients' Oncotype Dx (ODX RS) recurrence score distribution <26 (green) vs $\geq 26$ (blue) in the following four groups: low neutrophil-tolymphocyte ratio (NLR; <2.15) and low grade $(\mathrm{GI} / 2)$, low NLR and high grade $(G 3)$, high NLR $(\geq 2.15)$, and low grade, and high NLR and high grade $(\mathbf{A})$. Illustration showing the patients' ODX RS <16 (green) vs $\geq 16$ (blue) distribution in the four groups: absent (0), presence of any one (I), two (2), or all (3) of the following: high grade (G3), high NLR $\geq 2.15$, or high Ki-67 (>20) (B). 
A

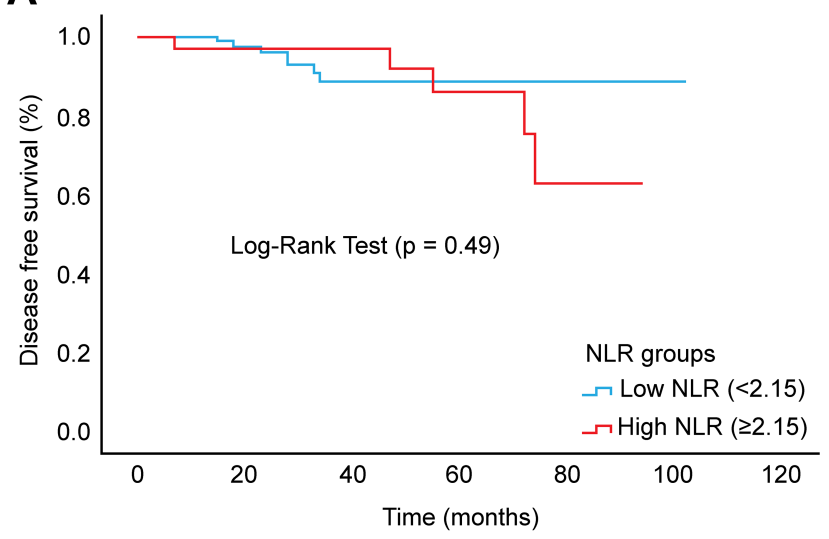

C

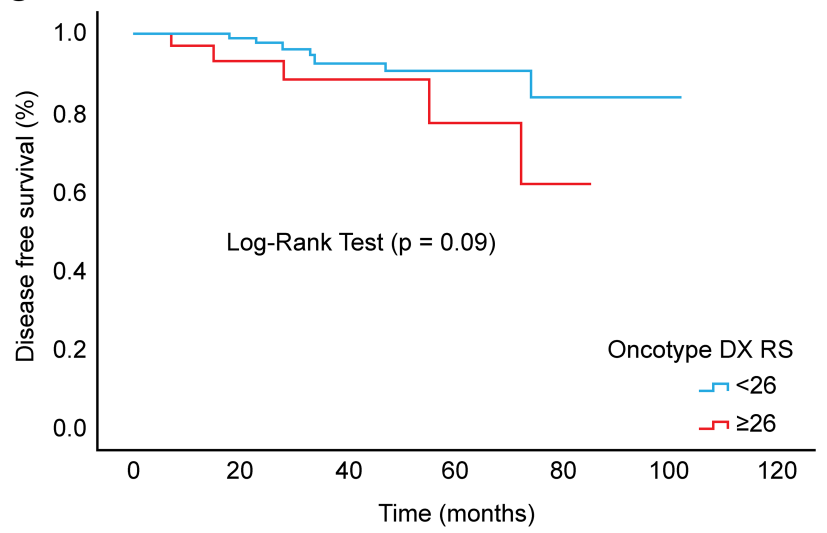

B

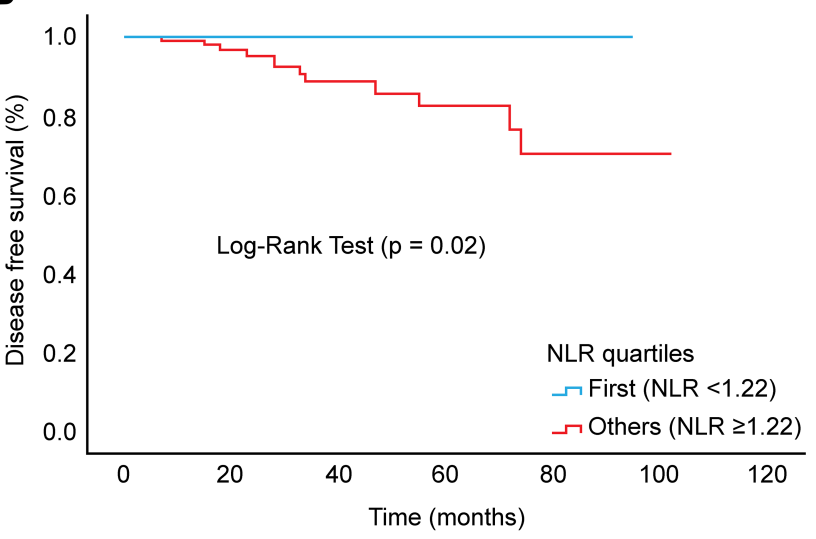

D

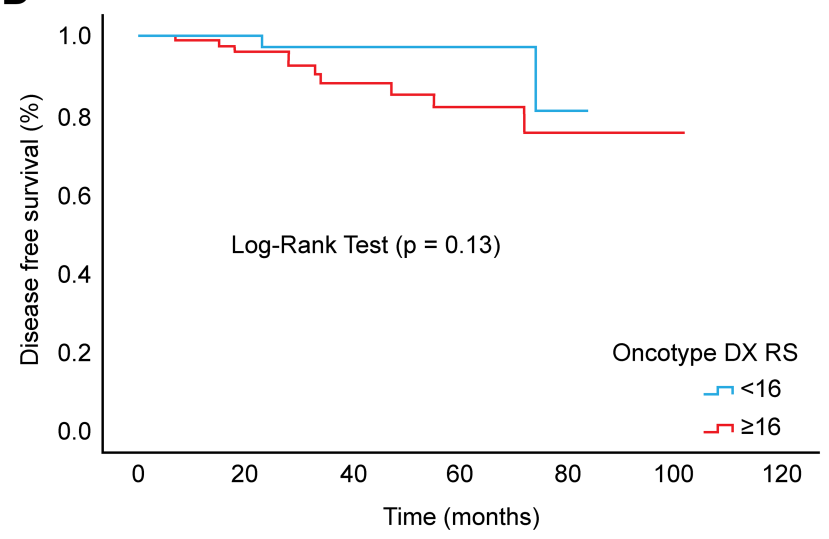

Figure 4 Disease-free survival of patients with neutrophil-to-lymphocyte ratio (NLR) of $<2.15$ vs $\geq 2.15$ (A), NLR $<1.22$ vs $\geq 1.22$ (B), Oncotype Dx (ODX RS) $<26$ vs $\geq 26$ (C), and ODX RS $<16$ vs $\geq 16$ (D).

guide adjuvant chemotherapy than either of the two alone. ${ }^{52}$ However, none of these models included NLR. As shown earlier, NLR has been linked to recurrence and survival in patients with $\mathrm{BC}$ from a clinical standpoint and play major roles in malignancy. ${ }^{19}$ We envisaged that pretreatment NLR could be an additive prognostic clinical factor for ODX RS. To investigate this possibility, we tested the pretreatment NLR value against actual ODX RS in our patients and then included NLR with other clinicopathological factors to predict RS.

To the best our knowledge, this is the first report of such a relationship between RS and preoperative NLR. However, Grenader et al found no association between the preoperative NLR as a predictor of ODX RS. ${ }^{35}$ A possible explanation for the differences could be attributed to the following factors: i) the NLR cutoff value of 2.5, which was obtained from a heterogeneous group of Asians with all BC subtypes (28.9\% HER2-positive and $22.3 \%$ triple-negative), with node positivity $(35 \%)^{33}$ and ii) the exclusion criteria for factors affecting the NLR were not specified in the previous study. ${ }^{35}$ These factors might have influenced the negative outcome as the median NLR/ optimal cutoff varies by disease characteristics, ethnicity, ${ }^{53,54}$ and systemic factors that are known to alter white blood cell counts. We obtained optimal cutoff values from the ROC curve and followed prespecified exclusion criteria, such as active infection, autoimmune diseases, and medications such as steroids (Figure 1).

We found that the tumor grade was strongly associated with RS, in accordance with previous studies. ${ }^{55,56}$ However, the tumor grade should be evaluated in the context of histology subtypes. ${ }^{56}$ In this cohort, most (94.4\%) patients had invasive ductal carcinoma and 5.6\% had invasive lobular carcinoma (ILC). In addition, the data of all patients with ILC had ODX RS of $<16$, except one with an RS of 23, are in agreement with those of previous studies, which have shown that ILC is not commonly associated with high ODX RS..$^{57,58}$

The leading strength of this study is that it included consecutive early-stage $\mathrm{BC}$ patients from a prospective database, following prespecified exclusion criteria and 
driven NLR from the same sample. The main limitations of this study include its single-center design, limited number of patients, and follow-up. The nature of early-stage $\mathrm{BC}$ necessitates a longer follow-up period to assess the secondary outcomes, DFS, and OS. However, these data encourage future research to determine NLR within one ethnicity and consider other factors affecting the NLR.

In summary, NLR as a continuous variable was associated with ODX RS and a cutoff point of 2.15 was an independent predictive factor of high RS $(\geq 26)$ and low RS $(<16)$. In particular, patients with a low NLR and G1/ G2 $(n=102)$ were more likely to have an RS of $<26$ (90 patients, $88 \%$ ). Moreover, the presence of any factor in the high category (Ki-67 status $\geq 20$, NLR $\geq 2.15$ ) or tumor G3 makes the patient unlikely to have low RS $(<16)$, and this chance further decreases as the number of these factors in the high category increases. Therefore, these findings suggest that NLR, tumor grade, and Ki-67 status are potential predictive biomarkers for RS. Nevertheless, the optimal NLR cutoff is a major limitation for utilization in clinical practice. Further larger studies are needed to determine the optimal cutoff point for HR+ early-stage BC considering ethnicity and systemic factors.

\section{Conclusion}

These observations suggest that preoperative NLR is a promising prognostic factor and could be additive to other clinicopathological variables in early-stage BC management. However, further studies are required to validate this hypothesis.

\section{Abbreviations}

BC, Breast cancer; BMI, Body mass index; DFS, Diseasefree survival; HR+, Hormone receptor-positive; HER2-, Human epidermal growth factor receptor 2-negative; IHC, Immunohistochemistry; ILC, Invasive lobular carcinoma; IQR, Interquartile range; LVI, Lymphovascular invasion; NLR, Neutrophil-to-lymphocyte ratio; ODX, Oncotype DX ${ }^{\circledR}$; OR, Odds ratio; OS, Overall survival; PLR, Platelet-to-lymphocyte ratio; RS, Recurrence score; ROC, Receiver operating characteristic.

\section{Data Sharing Statement}

All data generated or analyzed during this study are included in this published article.

\section{Statement of Ethics}

This study was approved by the Research Advisory Council of King Faisal Specialist Hospital \& Research Centre (RAC number 2051-029, and conducted following the ethical principles of the Declaration of Helsinki (2000). The participants remained anonymous, and no identifying or protected health information was recorded.

\section{Acknowledgments}

The authors thank breast cancer coordinator Ms. Monera for her help with data collection.

\section{Author Contributions}

All authors made a significant contribution to the work reported, whether that is in the conception, study design, execution, acquisition of data, analysis and interpretation, or in all these areas, took part in drafting, revising, or critically reviewing the article; gave final approval of the version to be published; have agreed on the journal to which the article has been submitted; and agree to be accountable for all aspects of the work.

\section{Funding}

There is no funding to report.

\section{Disclosure}

Dr. Taher Al-Tweigeri has received speaking honoraria from Roche, Novartis, and Lilly and has served as an advisory committee for these companies. The other authors declare no conflicts of interest.

\section{References}

1. Sung H, Ferlay J, Siegel RL, et al. Global cancer statistics 2020: GLOBOCAN estimates of incidence and mortality worldwide for 36 cancers in 185 countries. CA Cancer J Clin. 2021;71(3):209-249. doi: $10.3322 /$ caac. 21660

2. Howlader N, Altekruse SF, Li CI, et al. US incidence of breast cancer subtypes defined by joint hormone receptor and HER2 status. $J$ Natl Cancer Inst. 2014;106(5):dju055. doi:10.1093/jnci/dju055

3. Fallahpour S, Navaneelan T, De P, Borgo A. Breast cancer survival by molecular subtype: a population-based analysis of cancer registry data. CMAJ Open. 2017;5(3):E734-E739. doi:10.9778/cmajo.20170030

4. Kulkarni A, Stroup AM, Paddock LE, Hill SM, Plascak JJ, Llanos AAM. Breast cancer incidence and mortality by molecular subtype: statewide age and racial/ethnic disparities in new Jersey. Cancer Heal Disparities. 2019;3:e1-e17. doi:10.9777/chd.2019.1012

5. Noone AM, Cronin KA, Altekruse SF, et al. Cancer incidence and survival trends by subtype using data from the surveillance epidemiology and end results program, 1992-2013. Cancer Epidemiol Biomarkers Prev. 2017;26(4):632-641. doi:10.1158/1055-9965.EPI16-0520 
6. Dai X, Li T, Bai Z, et al. Breast cancer intrinsic subtype classification, clinical use and future trends. Am J Cancer Res. 2015;5 (10):2929-2943.

7. Kesson EM, Allardice GM, George WD, Burns HJG, Morrison DS. Effects of multidisciplinary team working on breast cancer survival: retrospective, comparative, interventional cohort study of 13722 women. BMJ. 2012;344:7856. doi:10.1136/bmj.e2718

8. Mansour EG, Gray R, Shatila AH, et al. Efficacy of adjuvant chemotherapy in high-risk node-negative breast cancer. $N$ Engl J Med. 1974;306(13):802-805.

9. Mansour EG, Gray R, Shatila AH, et al. Survival advantage of adjuvant chemotherapy in high-risk node-negative breast cancer: ten-year analysis - an intergroup study. J Clin Oncol. 1998;16 (11):3486-3492. doi:10.1200/JCO.1998.16.11.3486

10. Albain K, Anderson S, Arriagada R, et al. Comparisons between different polychemotherapy regimens for early breast cancer: meta-analyses of long-term outcome among 100000 women in 123 randomised trials. Lancet. 2012;379(9814):432-444. doi:10.1016/ S0140-6736(11)61625-5

11. Melisko M. A multigene assay to predict recurrence of tamoxifen-treated, node-negative breast cancer. Women's Oncol Rev. 2005;5(1):45-47. doi:10.1080/14733400500093379

12. Paik S, Tang G, Shak S, et al. Gene expression and benefit of chemotherapy in women with node-negative, estrogen receptor-positive breast cancer. $J$ Clin Oncol. 2006;24 (23):3726-3734. doi:10.1200/JCO.2005.04.7985

13. Sparano JA, Paik S. Development of the 21-gene assay and its application in clinical practice and clinical trials. J Clin Oncol. 2008;26(5):721-728. doi:10.1200/JCO.2007.15.1068

14. Albain KS, Barlow WE, Shak S, et al. Prognostic and predictive value of the 21-gene recurrence score assay in postmenopausal women with node-positive, oestrogen-receptor-positive breast cancer on chemotherapy: a retrospective analysis of a randomised trial. Lancet Oncol. 2010;11(1):55-65. doi:10.1016/S1470-2045(09) 70314-6

15. Kwa M, Makris A, Esteva FJ. Clinical utility of gene-expression signatures in early stage breast cancer. Nat Rev Clin Oncol. 2017;14(10):595-610. doi:10.1038/nrclinonc.2017.74

16. Sparano JA, Gray RJ, Makower DF, et al. Adjuvant chemotherapy guided by a 21-gene expression assay in breast cancer. $N$ Engl J Med. 2018;379(2):111-121. doi:10.1056/NEJMoa1804710

17. Sparano JA, Gray RJ, Makower DF, et al. Clinical outcomes in early breast cancer with a high 21-gene recurrence score of 26 to 100 assigned to adjuvant chemotherapy plus endocrine therapy: a secondary analysis of the TAILORx randomized clinical trial. JAMA Oncol. 2020;6(3):367-374. doi:10.1001/jamaoncol.2019.4794

18. Rizki H, Hillyar C, Abbassi O, Miles-Dua S. The utility of Oncotype DX for adjuvant chemotherapy treatment decisions in estrogen receptor-positive, human epidermal growth factor receptor 2-negative, node-negative breast cancer. Cureus. 2020;12(3):1-12. doi:10.7759/cureus. 7269

19. Hanahan D, Weinberg RA. Hallmarks of cancer: the next generation. Cell. 2011;144(5):646-674. doi:10.1016/j.cell.2011.02.013

20. Balkwill FR, Mantovani A. Cancer-related inflammation: common themes and therapeutic opportunities. Semin Cancer Biol. 2012;22 (1):33-40. doi:10.1016/j.semcancer.2011.12.005

21. Mantovani A, Allavena P, Sica A, Balkwill F. Cancer-related inflammation. Nature. 2008;454(7203):436-444. doi:10.1038/ nature 07205

22. Gonzalez H, Hagerling C, Werb Z. Roles of the immune system in cancer: from tumor initiation to metastatic progression. Genes Dev. 2018;32(19-20):1267-1284. doi:10.1101/GAD.314617.118

23. Denkert C, Loibl S, Noske A, et al. Tumor-associated lymphocytes as an independent predictor of response to neoadjuvant chemotherapy in breast cancer. J Clin Oncol. 2010;28(1):105-113. doi:10.1200/ JCO.2009.23.7370
24. Pattison CW, Pattison CW, Woods KL, Morrison JM. Lymphocytopenia as an independent predictor of early recurrence in breast cancer. $\mathrm{Br} J$ Cancer. 1987;55(1):75-76. doi:10.1038/ bjc. 1987.15

25. Azab B, Bhatt VR, Phookan J, et al. Usefulness of the neutrophil-tolymphocyte ratio in predicting short- and long-term mortality in breast cancer patients. Ann Surg Oncol. 2012;19(1):217-224. doi:10.1245/s10434-011-1814-0

26. Harowicz MR, Robinson TJ, Dinan MA, et al. Algorithms for prediction of the Oncotype DX recurrence score using clinicopathologic data: a review and comparison using an independent dataset. Breast Cancer Res Treat. 2017;162:1.

27. Yamanaka T, Matsumoto S, Teramukai S, Ishiwata R, Nagai Y, Fukushima M. The baseline ratio of neutrophils to lymphocytes is associated with patient prognosis in advanced gastric cancer. Oncology. 2008;73(3-4):215-220. doi:10.1159/000127412

28. Sarraf KM, Belcher E, Raevsky E, Nicholson AG, Goldstraw P, Lim E. Neutrophil/lymphocyte ratio and its association with survival after complete resection in non-small cell lung cancer. J Thorac Cardiovasc Surg. 2009;137(2):425-428. doi:10.1016/j.jtcvs.2008.05.046

29. Kishi Y, Kopetz S, Chun YS, Palavecino M, Abdalla EK, Vauthey JN. Blood neutrophil-to-lymphocyte ratio predicts survival in patients with colorectal liver metastases treated with systemic chemotherapy. Ann Surg Oncol. 2009;16(3):614-622. doi:10.1245/ s10434-008-0267-6

30. Templeton AJ, McNamara MG, Šeruga B, et al. Prognostic role of neutrophil-to-lymphocyte ratio in solid tumors: a systematic review and meta-analysis. J Natl Cancer Inst. 2014;106(6):1-11. doi:10.1093/jnci/dju124

31. Guo W, Lu X, Liu Q, et al. Prognostic value of neutrophil-tolymphocyte ratio and platelet-to-lymphocyte ratio for breast cancer patients: an updated meta-analysis of 17079 individuals. Cancer Med. 2019;8(9):4135-4148. doi:10.1002/cam4.2281

32. Wei B, Yao M, Xing C, et al. The neutrophil lymphocyte ratio is associated with breast cancer prognosis: an updated systematic review and meta-analysis. Onco Targets Ther. 2016;9:5567-5575. doi:10.2147/ott.s108419

33. Noh H, Eomm M, Han A. Usefulness of pretreatment neutrophil to lymphocyte ratio in predicting disease-specific survival in breast cancer patients. J Breast Cancer. 2013;16(1):55-59. doi:10.4048/ jbc.2013.16.1.55

34. Corbeau I, Jacot W, Guiu S. Neutrophil to lymphocyte ratio as prognostic and predictive factor in breast cancer patients: a systematic review. Cancers. 2020;12(4):958. doi:10.3390/ cancers12040958

35. Grenader T, Plotkin Y, Geffen DB. The preoperative neutrophil/ lymphocyte ratio does not correlate with the 21-gene recurrence score in estrogen receptor-positive breast cancer patients. Oncol Res Treat. 2015;38(1-2):24-27. doi:10.1159/000370341

36. Galon J, Pagès F, Marincola FM, et al. Cancer classification using the Immunoscore: a worldwide task force. J Transl Med. 2012;10(1). doi:10.1186/1479-5876-10-205

37. Koboldt DC, Fulton RS, McLellan MD, et al. Comprehensive molecular portraits of human breast tumours. Nature. 2012;490 (7418):61-70. doi:10.1038/nature11412

38. Faria SS, Fernandes PC, Silva MJB, et al. The neutrophil-tolymphocyte ratio: a narrative review. Ecancermedicalscience. 2016;10:1-12. doi:10.3332/ecancer.2016.702

39. McShane LM, Altman DG, Sauerbrei W, Taube SE, Gion M, Clark GM. REporting recommendations for tumor MARKer prognostic studies (REMARK). Breast Cancer Res Treat. 2006;100 (2):229-235. doi:10.1007/s10549-006-9242-8

40. Hayes DF, Ethier S, Lippman ME. New guidelines for reporting of tumor marker studies in breast cancer research and treatment: REMARK. Breast Cancer Res Treat. 2006;100(2):237-238. doi:10.1007/s10549-006-9253-5 
41. Nishijima TF, Deal AM, Williams GR, Guerard EJ, Nyrop KA, Muss HB. Frailty and inflammatory markers in older adults with cancer. Aging. 2017;9(3):650-664. doi:10.18632/aging.101162

42. Li J, Chen Q, Luo X, et al. Neutrophil-to-lymphocyte ratio positively correlates to age in healthy population. J Clin Lab Anal. 2015;29 (6):437-443. doi:10.1002/jcla.21791

43. Rashmi Kumar N, Burns J, Abraham J, et al. NCCN guidelines version 1.2022 breast cancer; 2021. Available from: https://www. nccn.org/guidelines. Accessed December 4, 2021.

44. Chen Y, Chen K, Xiao X, et al. Pretreatment neutrophil-tolymphocyte ratio is correlated with response to neoadjuvant chemotherapy as an independent prognostic indicator in breast cancer patients: a retrospective study. BMC Cancer. 2016;16(1):1-12. doi:10.1186/s12885-016-2352-8

45. Ademuyiwa FO, Miller A, O'Connor T, et al. The effects of oncotype DX recurrence scores on chemotherapy utilization in a multi-institutional breast cancer cohort. Breast Cancer Res Treat. 2011;126(3):797-802. doi:10.1007/s10549-010-1329-6

46. Zhang L, Hsieh MC, Petkov V, et al. Trend and survival benefit of Oncotype DX use among female hormone receptor-positive breast cancer patients in 17 SEER registries, 2004-2015. Breast Cancer Res Treat. 2020;180(2):491-501. doi:10.1007/s10549-020-05557-x

47. Klein ME, Dabbs DJ, Shuai Y, et al. Prediction of the Oncotype DX recurrence score: use of pathology-generated equations derived by linear regression analysis. Mod Pathol. 2013;26(5):658-664. doi:10.1038/modpathol.2013.36

48. Gage MM, Rosman M, Mylander WC, et al. A validated model for identifying patients unlikely to benefit from the 21-Gene recurrence score assay. Clin Breast Cancer. 2015;15(6):467-472. doi:10.1016/j. clbc.2015.04.006.A

49. Tang G, Cuzick J, Costantino JP, et al. Risk of recurrence and chemotherapy benefit for patients with node-negative, estrogen receptor-positive breast cancer: recurrence score alone and integrated with pathologic and clinical factors. J Clin Oncol. 2011;29 (33):4365-4372. doi:10.1200/JCO.2011.35.3714

50. Dodson A, Okonji D, Assersohn L, et al. Discordance between oncotype DX recurrence score and RSPC for predicting residual risk of recurrence in ER-positive breast cancer. Breast Cancer Res Treat. 2018;168(1):249-258. doi:10.1007/s10549-017-4514-Z
51. Crolley VE, Marashi H, Rawther S, et al. The impact of Oncotype DX breast cancer assay results on clinical practice: a UK experience. Breast Cancer Res Treat. 2020;180(3):809-817. doi:10.1007/s10549020-05578-6

52. Sparano JA, Crager MR, Tang G, Gray RJ, Stemmer SM, Shak S. Development and validation of a tool integrating the 21-gene recurrence score and clinical-pathological features to individualize prognosis and prediction of chemotherapy benefit in early breast cancer. J Clin Oncol. 2020;39(6). doi:10.1200/jco.20.03007

53. Bain BJ. Ethnic and sex differences in the total and differential white cell count and platelet count. J Clin Pathol. 1996;49(8):664-666. doi:10.1136/jcp.49.8.664

54. Azab B, Camacho-Rivera M, Taioli E. Average values and racial differences of neutrophil lymphocyte ratio among a nationally representative sample of United States subjects. PLoS One. 2014;9(11): e112361. doi:10.1371/journal.pone.0112361

55. Sparano JA, Gray RJ, Makower DF, et al. Prospective validation of a 21-gene expression assay in breast cancer. $N$ Engl J Med. 2015;373 (21):2005-2014. doi:10.1056/NEJMoa1510764

56. Singh K, He X, Kalife ET, Ehdaivand S, Wang Y, Sung CJ. Relationship of histologic grade and histologic subtype with oncotype Dx recurrence score; retrospective review of 863 breast cancer oncotype Dx results. Breast Cancer Res Treat. 2018;168(1):29-34. doi:10.1007/s10549-017-4619-4

57. Conlon N, Ross DS, Howard J, Catalano JP, Dickler MN, Tan LK. Is there a role for oncotype Dx testing in invasive lobular carcinoma? Breast J. 2015;21(5):514-519. doi:10.1111/tbj.12445

58. Kizy S, Huang JL, Marmor S, Tuttle TM, Hui JYC. Impact of the 21-gene recurrence score on outcome in patients with invasive lobular carcinoma of the breast. Breast Cancer Res Treat. 2017;165 (3):757-763. doi:10.1007/s10549-017-4355-9

\section{Publish your work in this journal}

Cancer Management and Research is an international, peer-reviewed open access journal focusing on cancer research and the optimal use of preventative and integrated treatment interventions to achieve improved outcomes, enhanced survival and quality of life for the cancer patient.
The manuscript management system is completely online and includes a very quick and fair peer-review system, which is all easy to use. Visit http://www.dovepress.com/testimonials.php to read real quotes from published authors. 